\title{
LA MEMORIA INDOLORA DEL VIDEOJUEGO DE HISTORIA
}

\author{
ITHE PAINLESS MEMORY OF THE HISTORICAL VIDEO GAMES
}

\author{
Alberto Venegas Ramos \\ Universidad de Murcia. Murcia / España \\ alberto.venegasr@um.es \\ https://orcid.org/0000-0002-5621-7749
}

Recibido/Received: 15/05/2020

Modificado/Modified: 03/07/2020

Aceptado/Accepted: 25/09/2020

\section{RESUMEN}

El videojuego de historia, bajo su condición de memoria, tiene dos formas de relacionarse con el pasado: construir o reconstruirlo, es decir, pueden reflejar o pueden ignorar el dolor de las víctimas y convertir el pasado en un parque de atracciones. El objetivo de este trabajo será tratar de demostrar el axioma anterior. La metodología empleada será aplicar de manera comparativa estos dos conceptos acuñados por Walter Benjamin, comentados por Reyes Mate e interpretados por Tzvetan Todorov o Enzo Traverso a diferentes juegos que reúnen las características descritas por los teóricos anteriores para cada una de las categorías. Este este estudio comparativo nos proporcionará una serie de resultados y conclusiones teóricas que apuntan al nacimiento de una cultura de la conmemoración dentro del videojuego a partir de una construcción ludonarrativa particular del ayer.

\section{PALABRAS CLAVE}

Identidad; memoria; historia; Walter Benjamin; Gilles Lipovetsky.

\section{SUMARIO}

1. Introducción. 2. Objetivos. 3. El deber de la memoria en el videojuego de historia. 4. Conclusiones. Bibliografía.

\begin{abstract}
The video game of history, under its condition of memory, has two ways of relating to the past: building or rebuilding it, they can reflect or ignore the pain of the victims and turn the past into an amusement park. The objective of this work will be to try to demonstrate the previous axiom. The methodology used will be to apply comparatively these two concepts coined by Walter Benjamin, commented by Reyes Mate and interpreted by Tzvetan Todorov or Enzo Traverso to different games that meet the characteristics described by previous theorists for each of the categories. This comparative study will provide us with a series of results and theoretical conclusions that point to the birth of a culture of commemoration within the video game from a particular ludonarrative construction of yesterday.
\end{abstract}

\section{KEYWORDS}

Identity; Memory; History; Walter Benjamin; Gilles Lipovetsky.

\section{CONTENTS}

1. Introduction. 2. Objetives. 3. The duty of memory in the video games of history. 4. Conclusions. References. 


\section{INTRODUCCIÓN}

En el año 1978 apareció en el mercado el primer videojuego ambientado en la Segunda Guerra Mundial. Desde entonces la conflagración mundial se ha convertido en un género temático fundamental del videojuego que ha conseguido una inmensa popularidad. Sin embargo, en ninguno de estos títulos, salvo uno y de reciente aparición Trough the Darkest of Times, (Paintbucket Games, 2020) aparece el ascenso del nazismo. En todos ellos el movimiento encabezado por Adolf Hitler aparece ya consolidado, en el poder, armado y en píe de guerra. Ningún título, hasta el día de hoy, había tratado de explicar el surgimiento del Tercer Reich. Weimar no existía para el videojuego (Venegas, 2018).

La causa probable de esta situación puede buscarse en cientos de lugares entre los que destacan la necesidad de interactividad del videojuego (Venegas, 2018b) y el predominio del apartado visual fotorrealista (Venegas, 2020). Al jugador hay que proporcionarle retos y objetivos constantemente para superar y éstos deben tener un cariz espectacular que logre captar el interés. Estos dos condicionantes obligan al desarrollador de videojuegos a buscar momentos interactivos y escenas que llamen poderosamente la atención del jugador, una búsqueda que desemboca, en la mayoría de las ocasiones, en la guerra y la violencia armada, una norma aplicada a la representación de todas las épocas históricas (Jiménez, 2011, 2014). El contexto queda aparcado y Weimar forma parte de ese contexto.

Al hallar la espectacularidad visual y la necesidad interactiva en la guerra la tarea principal del creador del videojuego es sumergir al jugador en dicho conflicto armado, en un choque violento que no debe ser inerme o cotidiano, es decir, el soldado no puede dedicarse a tareas de reconocimiento o de correo, no son tareas espectaculares, el soldado debe vivir en un frente perpetuo en el que matar con un fusil al hombro fuese la norma. En el videojuego Weimar queda relegada por Normandía (Venegas, 2019).

Al copar las acciones armadas del soldado la mayoría de los mensajes e imágenes de los videojuegos la sociedad civil quedaba aparcada. La Segunda Guerra Mundial se ha reducido por completo a un campo de batalla en el que todos los ejércitos son iguales. Una decisión potenciada por la eliminación de cualquier símbolo como la esvástica por algunos videojuegos o la ocultación de grupos militares alemanes como las SS (Venegas, 2017; Chapman y Linderoth, 2015: 140), una situación que ya corrió paralela en el ámbito del cine (Sand, 2004: 281-282). La sociedad civil dejaba de existir y la guerra se convertía en un parque de atracciones donde jugar a policías y ladrones. Los hechos más trágicos, como el genocidio, quedaban enterrados porque, al fin y al cabo, lo que los desarrolladores de videojuegos buscaban ofrecer a su público eran juegos interactivos, atractivos y seductores que fueran rentables.

Esta es la descripción de la gran mayoría de videojuegos de la Segunda Guerra Mundial (Ramsay, 2015), sin embargo, desde hace unos años hasta la actualidad y gracias a los estudios más pequeños e independientes, han comenzado a surgir un nuevo tipo de títulos que están rompiendo con la memoria estética (Venegas Ramos, 2020b) del evento gracias a su ruptura con la espectacularidad y a la búsqueda de la interactividad en otros lugares. Obras como la vanguardista Venti Messi (We Are Muesli, 2016) sitúa al jugador en la posición del testigo durante la guerra en Italia. La sociedad civil cobra protagonismo y el conflicto no se narra desde las posiciones del bien absoluto, los Aliados, y el mal absoluto, el Eje. Los grises entran en escena. Un camino que han seguido otros como My Child Lebensborn (Sarepta Studios, 2018). Un videojuego que propone al jugador gestionar la educación y las relaciones sociales de un niño fruto de la ocupación alemana de Noruega. Los lugares de la memoria estética más reconocidos, el noroeste de Francia durante los años 1944 y 1945, dan paso a 
otros lugares menos representados en el videojuego, como la República Checa. El título Attentat 1942 (Charles Games, 2018) propone al jugador conocer la situación del Protectorado de Bohemia y Moravia bajo la dominación nazi y el gobierno de las SS durante la guerra, además del atentado perpetrado en Praga contra el gobernador del Protectorado, Reinhard Heydrich, uno de los ideólogos del Holocausto. El videojuego, gracias a la escena independiente, ha comenzado a explorar otros mensajes e imágenes del nazismo y la Segunda Guerra Mundial demostrando que pueden ser parte de la conmemoración. Un camino que ha coronado el título Through the Darkest of Times (Paintbucket Games, 2020).

Estas dos formas de encarar la memoria, una dolora, basada en construir de nuevo el sufrimiento de aquellos que la padecieron y cuyo objetivo es construir un ayer que conecte con nuestro presente ofreciendo ejemplos o advertencias, y otra memoria indolora, que ignora el dolor de las víctimas y cuyo objetivo es reconstruir un pasado que sirva como parque de atracciones para el presente, son las dos formas fundamentales de acercarse al ayer en el videojuego. Se erige esta forma de observar el videojuego de historia como diferente a la más utilizada habitualmente, la desarrollada por Adam Chapman, quien diferenciaba entre "simulación conceptual" y "simulación realista" (2016: 61-75), una forma asociada al discurso historiográfico del videojuego de historia, muy diferente a la auspiciada por nosotros, que tal y como hemos expresado consideramos al videojuego de historia una forma de memoria. Una forma de entenderlo que nos aleja también de los trabajos dedicados a calibrar la autenticidad o la verosimilitud del medio (Wilhelm y Elliott, 2013), entre los que destaca los llevados a cabo por Juan Francisco Jiménez Alcázar (2016, 2016b).

Es importante señalar que partes de este trabajo ya han aparecido de manera fragmentaria en publicaciones no académicas (Venegas, 2019c; Venegas, 2020c, y Venegas, 2020d). Versiones bajo las que fue cobrando forma este artículo definitivo sobre el tema que trata de esclarecer las posibilidades del videojuego para interpretar un papel, o no, dentro de la cultura de la conmemoración que sitúa a la víctima en el centro de la memoria.

\section{OBJETIVO}

La intención principal de este artículo es explorar este cruce de caminos a la luz de los conceptos acuñados por Walter Benjamin rekonstruktion y konstruktion. A lo largo del artículo podremos observar la existencia de videojuegos que desean recordar el pasado con distintos objetivos. Algunos, como This War of Mine (11 bit studios, 2014), buscan advertir sobre los acontecimientos que representan para que éstos no vuelvan a suceder, otros, como Call of Duty: WWII (Sledgehammer Games, 2018), desean continuar la memoria estética de un conflicto y unos pocos, como Temporality (James Earl Cox III, 2014) o el ya citado Venti Messi, tratan de subvertir la memoria de aquello que muestran. Existen otros que no desean recordar y su intención es presentar al jugador un escenario estilizado basado en contenidos históricos para su disfrute y satisfacción personal, como Wolfenstein II: The New Collosus (MachineGames, 2017) o Battlefield V (DICE, 2018). Esta diferencia se ha tratado en otros artículos separando los títulos en diferentes formas; individual, colectiva, oficial o estética (Venegas, 2020); y objetivos; literal o ejemplar (Venegas, 2020c).

La razón principal por la que se han seleccionado las obras comentadas en este artículo se debe a nuestra intención de ofrecer el mayor contexto y contraste posible entre las dos formas de acercarse al pasado mencionadas: la reconstrucción y la construcción. Por ello se han escogido obras que tratan explícitamente de construir un nuevo ayer para el presente del videojuego, como Through the Darkest of Times (Paintbucket Games, 20120), My Child 
Lebensborn (Serapta Studios, 2017) o Venti Messi (We Are Muesli, 2016). Todos ellos juegos que rompen lo establecido en el medio y provocan una ruptura con la memoria estética fijada sobre la Segunda Guerra Mundial en el videojuego. Y al contrario, para ofrecer el contraste necesario hemos seleccionado títulos que reproducen esa memoria estética y los discursos sobre el conflicto más representados en los medios de comunicación de masas, como Call of Duty: WWII, Warsaw (Pixelated Milk, 2019) o My memory of us (Juggler Games, 2018).

\section{EL DEBER DE LA MEMORIA EN EL VIDEOJUEGO DE HISTORIA}

La historia y la memoria son dos formas diferentes, aunque entrelazadas, de acercarnos al pasado. Tal y como expresa Reyes Mate en su obra El tiempo, tribunal de la historia:

Hablemos, pues, del deber de memoria. Notemos que no hablamos, por ejemplo, de deber de historia y sí de deber de memoria. No hay deber de historia porque el conocimiento de los hechos es un momento más del conocer al que estamos obligados por solidaridad con la especie (...) A la memoria, sin embargo, si asociamos la idea de deber para dar a entender que el conocimiento que la memoria propone funciona de otra manera. Esa diferencia cognitiva entre historia y memoria (...) se expresa de muchas maneras (2018: 15) (...) De repente el pasado se carga de exigencia moral. El pasado no debe ser recordado solo more histórico, sino también more ethico (...). Recordar es re-pensar (2018: 14).

El recuerdo y la memoria, de acuerdo a Reyes Mate siguiendo la conocida tesis de Adorno, en la que establecía que «Hitler ha impuesto a los hombres un nuevo imperativo categórico para su actual estado de esclavitud: el de orientar su pensamiento y su acción de modo que Auschwitz no se repita, que no vuelva a ocurrir nada semejante» (Reyes, 2008: 111), exigen una razón ética, un deber que nos exige un cambio en las formas con las que nos relacionamos con el presente. A la vez también nos exige una nueva formar de construir la historia, a través de los ojos de la víctima (Reyes, 2008: 72). Cómo hemos podido observar, este deber asociado al recuerdo no se encuentra presente en todos los videojuegos examinados. Muchos de ellos escapan de este imperativo categórico y mantienen una postura indolora ante lo sucedido. La mayoría de los títulos bélicos esconden a la sociedad civil y no muestran los padecimientos que ésta sufrió durante las guerras mundiales. Esta situación podría explicarse a través de la configuración del videojuego como medio de comunicación de masas y su pretensión de accesibilidad universal. Un punto medio entre las reflexiones sobre cómo se ha narrado las guerras hechas por el historiador militar Victor David Hanson contenidas en las citas destacadas al comienzo su obra Matanza y cultura y las realizadas por Lipovetsky sobre la ética de nuestros tiempos:

En las descripciones bélicas, los eufemismos o las omisiones (...) pueden constituir una ofensa criminal. No es casualidad que los autores de talento que se han ocupado de las guerras equiparen las tácticas a la sangre, la estrategia a los cadáveres. ¿Cómo es posible escribir sobre los asuntos culturales más amplios que rodean a la guerra sin describir que se les hurta su juventud, que sus robustos cuerpos empapan de sangre los campos de batalla? (2004). 
En esto reside la excepcional novedad de nuestra cultura ética: por primera vez, ésta es una sociedad que, lejos de exaltar los órdenes superiores, los eufemiza y los descredibiliza, una sociedad que desvaloriza el ideal de abnegación estimulando sistemáticamente los deseos inmediatos, la pasión del ego, la felicidad intimista y materialista (Lipovetsky, 2006: 12).

En la encrucijada de estos dos párrafos se encuentra el deber de la memoria y el recuerdo en el videojuego. De la guerra virtual e interactiva se ha eliminado la muerte, la sangre, el robo de la juventud y la miseria del campo de batalla. Del recuerdo del conflicto se ha ocultado a la víctima, sus cuerpos han desaparecido. La violencia armada ha perdido, en su representación, el deber ético y ha abrazado la satisfacción y la felicidad íntima del jugador que acaba con la vida del otro con un disparo a su cabeza. La memoria o la especulación ya no obligan al recuerdo ni al deber, obligan a la satisfacción y exigen al creador forjar su obra en el molde de la diversión, la satisfacción y la rentabilidad. Tal y como anunció Enzo Traverso, el pasado se ha transformado, en los medios, en un objeto de consumo "estetizado, neutralizado y rentabilizado listo para que la industria del turismo y del espectáculo lo recupere y utilice" (2011: 14).

Este cruce de caminos se bifurca en dos direcciones. La primera dirección, salvaje, poco explorada y difícil de transitar, es la memoria asociada al deber, aquello que Walter Benjamin denominaba Konstruktion, de acuerdo a Reyes Mate:

El concepto de Konstruktion, sin embargo, connota la ruptura del hilo de Ariadna que explica la Rekonstruktion, o como dice Benjamon «supone una previa destrucción». Rompe la continuidad histórica. Veamos cómo. La Konstruktion alcanza el pasado no por el camino real de la tradición, de lo existente, sino mediante un salto al vacio (...). Al saltar hacia un pasado que no tiene conexión con el presente, hacemos presente algo nuevo. Esa presencia inédita es, por un lado, destrucción o crítica del presente-dado y, por otro, creación o apuesta por un presente пиеvо (2008: 71).

El primer tipo de videojuego de historia que hemos observado rompe el hilo de la memoria estética como consecuencia de su ruptura con los retrolugares canónicos del tiempo y el lugar elegidos y consolidados mediante las mediaciones maestras más importantes. Venti Messi situaba al jugador un escenario por completo diferente al acostumbrado en las ficciones videolúdicas ambientadas en la Segunda Guerra Mundial más populares (Ramsay, 2015: 162-196). Un camino que continúa un título comercial: el trabajo alemán Through the Darkest of Times. Esta obra es una interesante propuesta independiente que mezcla la estrategia, la simulación y la aventura en un escenario poco conocido para el videojuego: los últimos coletazos de la Alemania de Weimar y los años de ascenso del nazismo, es decir, la década de 1930. La Segunda Guerra Mundial está muy representada en el videojuego y sin embargo ésta se reduce a una imagen fija: aquello que ocurre en Europa occidental desde el verano de 1944 a la primavera de 1945. Sus responsables son conscientes de este hecho y así lo aclaran en una entrevista ofrecida a Gameindustry:

Los videojuegos no cuentan la historia completa y permiten que los grupos neonazis recluten y crezcan en torno a las comunidades de jugadores, [...] la Segunda Guerra Mundial es un evento que traumatizó a generaciones y quebró todos los tabúes de la civilización. Si bien los videojuegos no son responsables exclusivos de 
esta situación, actualmente hacen muy poco para enmendarla [...] No debemos evitar la controversia y al mismo tiempo blanquear la Segunda Guerra Mundial y los crímenes de guerra [...] Los juegos pueden y deben ser un parte importante de la conmemoración (Taylor, 2019).

El estudio alemán desea crear con su propuesta una memoria que ate al jugador al deber de recordar, que logre advertirlo sobre lo sucedido en el pasado y le ayude a encarar el futuro con herramientas cada vez más útiles. Su intención es encarnar virtualmente la llamada memoria ejemplar acuñada por Todorov, en la que el pasado se convierte en un principio de acción para el presente (Todorov, 2013: 33-34). Through the Darkest of Times desea formar parte de la conmemoración de la guerra, del deber de recordar lo sucedido y avisar sobre que sucede cuando la intolerancia, el odio, la rabia y la violencia dominan la política. Y lo que es más importante, desean afrontar su propio pasado, el pasado de su país a través del recuerdo, no normalizarlo ni convertirlo en espectáculo, sino en materia de conmemoración y reflexión. Un objetivo que Reyes Mate asocia a la memoria: "El deber de memoria cuestiona la identidad nacional de cada pueblo pero también la forma de construir la historia" (2018: 17).

Todos estos títulos tratan de recuperar un pasado olvidado para traerlo al presente y obligar al jugador a reflexionar sobre lo sucedido para transformar su pensamiento y acción, reorientado, tras la experiencia del videojuego, hacia la víctima.

Si regresamos al cruce de caminos en el que nos encontrábamos con anterioridad el otro camino que no hemos tomado, en lo que se refiere al deber de recordar, es aquel que Benjamin denominaba Rekonstruktion y que Reyes Mate interpreta como:

La "reconstrucción”, al igual que el historicismo, se refiere al pasado que está presente, al pasado que ha ido tejiendo un sutil hilo de Ariadna entre el pasado y el presente, es decir, un pasado que ha cristalizado en tradiciones reconocidas en virtud de las cuales podemos transitar desde el pasado al presente. Ese hilo de Ariadna o empatía permite representar el pasado como garantía de origen del presente. La «reconstrucción» del pasado sería la actualización de un pasado que siempre ha estado presente en la tradición como fundamento implícito del presente-dado. La «reconstrucción» sería pues como la legitimización por el origen del presente que es la parte victoriosa de la historia. La "reconstrucción", como el historicismo, es ideología de los vencedores (2008: 71).

A lo largo de esta vía encontraremos al segundo tipo de videojuego de historia tratado, que son la mayoría títulos que se presentan a sí mismos como puente entre pasado y presente y que han ido perpetuándose a través de la generación de una memoria estética utilizada, en muchas ocasiones, por la memoria oficial y asociada al espectáculo y la satisfacción. Sin embargo, esta vía ya no encaja en la definición de camino, su éxito y su numeroso nivel de tránsito ha logrado convertirla en una autopista de seis canales que amenaza con acabar con la vida del resto de opciones. Por ella no solo fluyen las grandes producciones, existen otras pequeñas producciones que logran perpetuar, bajo la fórmula de memoria literal acuñada por Todorov bajo la que el pasado queda sometido al presente (2013: 34), el ayer como lugar de origen del presente. Sirvan de ejemplo los títulos polacos My Memory of Us (Juggler Games, 2018) y Warsaw (Paintbucket Games, 2019).

El primer de ellos guarda una clara similitud con otro videojuego, My Child Lebensborn, que nos permite realizar un contraste práctico entre los conceptos de Rekonstruktion y Konstruktion de Benjamin y los conceptos de literalidad y ejemplaridad de Todorov. My 
Child Lebensborn es un videojuego noruego creado por el estudio Sarepta Studio AS y My Memory of Us, de origen polaco, es obra del estudio Juggler Games. Ambos comparten una serie de similitudes evidentes a nivel de producción y a nivel de contenidos, aunque difieren en cuanto al objetivo, al deber de la memoria. En los dos títulos los protagonistas son niños. En el primero el personaje principal es un progenitor soltero que debe lidiar con la educación y el crecimiento de su hijo, nacido durante la guerra con una pareja miembro de la ocupación alemana. Esta simple descripción ya se opone a todo lo estudiado en este trabajo y rompe con el hilo de Ariadna de la memoria estética: hegemonía de lo militar, ausencia de niños o jóvenes, ocultamiento de la sociedad civil, etc. El reto, dentro de la partida, parte del momento en el que niño, o niña, acude al colegio y comienza a comprender su origen. Será en esta comprometida situación cuando, como padre del joven, el jugador deberá guiarlo construyendo un relato emocional que le ayude a superar los momentos de conflicto surgidos durante las horas de colegio.

Este hecho, el nacimiento de hijos durante la guerra en territorio ocupado, fue un problema que se extendió por todos los países participantes del conflicto, tanto Alemania como el resto de países ocupados por otros Estados como la URSS. Tal y como estudió Miriam Gebhardt en su libro Crimes Unspoken: The Rape of German Women at the End of the Second World War el nacimiento de hijos ilegítimos como consecuencia de la violación de mujeres supuso un grave problema para muchos países, especialmente durante la época de posguerra en la que muchas mujeres fueron acusadas injustamente de confraternizar con el enemigo. Un problema igual o más grave que el ocurrido en el Pacífico, donde muchas mujeres fueron obligadas a prostituirse y convertirse en esclavas sexuales de los oficiales japoneses, como describen George L. Hicks e Iris Chang en sus obras respectivas The comfort women: Japan's brutal regime of enforced prostitution in the Second World War y La violación de Nanking: el holocausto olvidado de la Segunda Guerra Mundial.

Por lo tanto, nos encontramos ante un problema bien documentado que ha pasado desapercibido hasta este momento por las grandes producciones y representaciones de la época. Las violaciones y más aún, la educación y formación de los hijos nacidos como producto de esas violaciones, no han pasado a formar parte de la memoria estética del momento histórico a través de su transformación en retrolugares y, por lo tanto, no han sido tomadas nunca en cuenta para crear obras con pretensión de literalidad histórica.

Además de este problema existe un claro obstáculo de diseño para crear una obra que represente este pasado concreto bajo los auspicios de la diversión, la seducción y la rentabilidad. My Child Lebensborn es, en definitiva, un raro ejemplo de memoria ejemplar que trata de advertir al jugador sobre el pasado complejo y complicado de un territorio con la intención de no olvidar lo sucedido para evitar que vuelva a suceder.

My Memory of Us difiere del videojuego noruego en aspectos esenciales, el primero de ellos es en su apariencia ligada a la ciencia ficción y la fábula. El planteamiento del juego es sencillo, una niña debe rescatar a otro niño que recuerda a los representados como judíos en las producciones mediáticas sobre el hecho. Para hacerlo sorteará a los enemigos y resolverá distintos puzles que alejen a la pequeña pareja del peligro. Este planteamiento guarda una profunda relación con el actual estado de la memoria de la Segunda Guerra Mundial en Polonia. En la escena polaca ha aparecido, junto con My memory of us el título Warsaw y ambos representan la facilidad con la que la memoria colectiva puede transformarse. El segundo título representa a la ciudad de Varsovia como un núcleo de guerrilleros que luchan por expulsar a los alemanes de la ciudad. Ambos títulos representan la negación absoluta del antisemitismo polaco y su postura activa ante la ocupación alemana. Estas dos nuevas formas de representación del pasado han surgido recientemente de acuerdo a las nuevas leyes 
aprobadas por el gobierno polaco en los últimos años y sirven de puente entre el pasado y el presente, un caso muy diferente al de My Child Lebensborn, que dinamita los puntos trazados en la memoria oficial noruega sobre el conflicto. Estas nuevas leyes prohíben terminantemente mencionar la responsabilidad o corresponsabilidad polaca en los crímenes alemanes contra los judíos (Rae, 2019) y son el resultado de un nuevo cambio en la percepción histórica del comportamiento polaco bajo la ocupación, enfocado ahora hacia su representación como héroes o mártires contra el fascismo (Tonini, 2019).

La prueba visual de esta afirmación se encuentra en dos lugares que ejemplifican a la perfección este cambio en la percepción del momento histórico. Una de las imágenes más reconocidas por el público de la película La lista de Schindler (Steven Spielberg, 1994), ambientada en Polonia, es la de una niña con vestido rojo que se encuentra sumergida entre la multitud de prisioneros alemanes (Ilustración 1).

La película de Spielberg se erigió en mediación maestra para el resto de producciones artísticas de masas posteriores y configuró la memoria estética del momento (SánchezBiosca, 2006: 151). My Memory of Us logra cambiar en su propuesta esta memoria estética y presenta a la misma niña vestida de rojo como agente activo de la liberación de judíos:

En la imagen podemos apreciar como la niña vestida con el mismo abrigo de rojo, representado a la población polaca, ayuda a escapar de la amenaza alemana a un niño caracterizado como judío (Ilustración 2). Existe, por tanto, en el contraste entre estas dos imágenes, dos formas de recordar lo sucedido en Polonia, una forma pasiva en la que la población espera su rescate y otra forma activa en la que es la propia población la que rescata.

Este cambio en la memoria colectiva del país se presencia de una forma mucho más cristalina en el videojuego Warsaw. En él aparecen personajes representados con los trajes grises a rayas representativos de los campos de trabajo los que, en 1944 (Ilustración 3), cogen las armas para liberar Varsovia de la ocupación alemana acompañando al resto de la población polaca.

\section{Ilustración 1: La niña con el abrigo rojo}

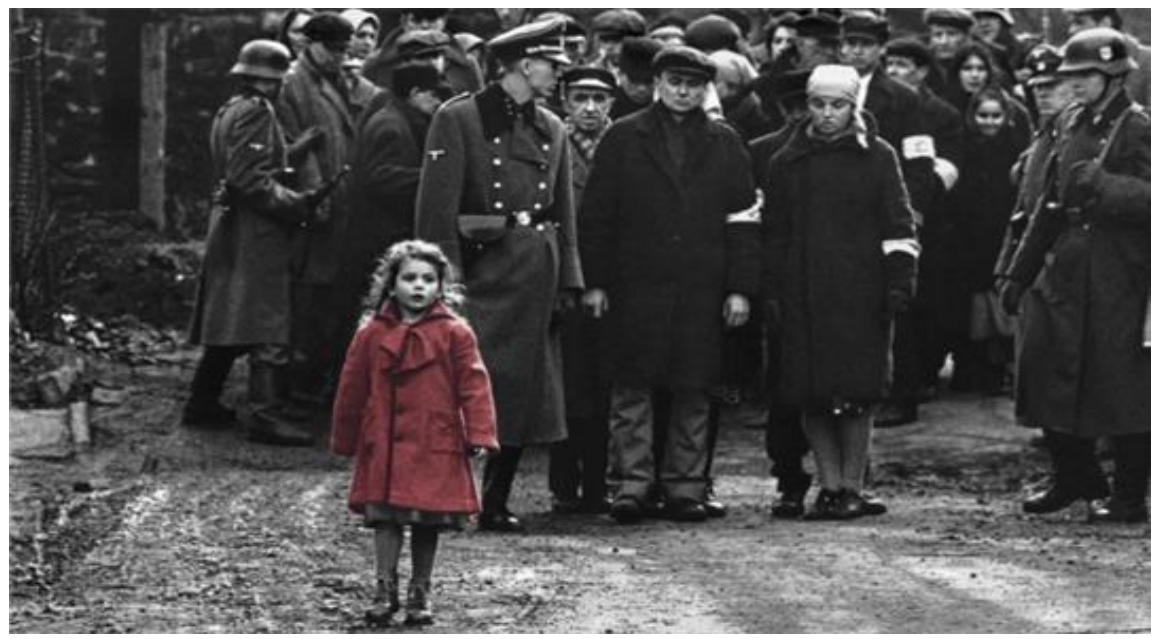

Fuente: Captura de pantalla de la Película La lista de Schindler. El abrigo volverá a verse al final de la cinta, abandonado ya por su antigua propietaria. 
Ilustración 2: Joven con un abrigo rojo salvando, activamente, a un joven ataviado con ropas estéticamente asociadas a la representación judía en los medios de comunicación.

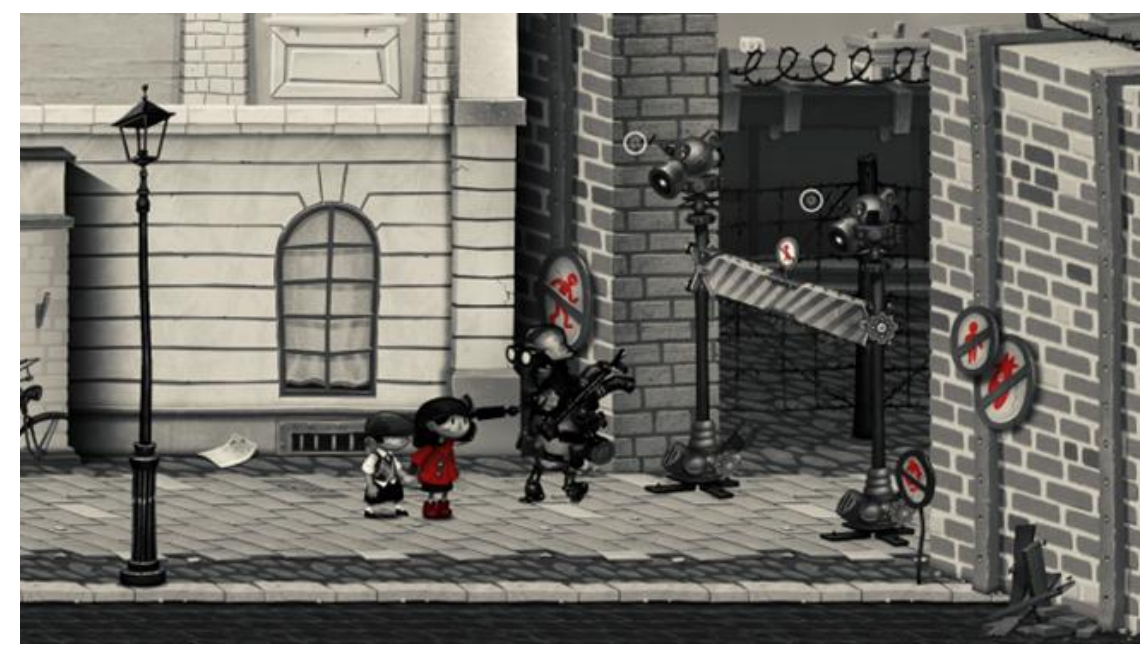

Fuente: Captura de pantalla de My Memory of Us.

La intención de este título es similar a la de otros anteriores como Enemy Front y que Piotr Sterczewski define en su trabajo «This Uprising of Mine: Game Conventions, Cultural Memory and Civilian Experience of War in Polish Games» como "ejemplos de juegos que tienen como objetivo reforzar la identidad nacional mediante la propagación de una determinada visión de la historia y lograr el éxito como productos comerciales de entretenimiento interactivo" (Sterczewski. 2016).

Ilustración 3: Imagen promocional del videojuego WARSAW utilizada por el estudio responsable para hacer promoción de su obra

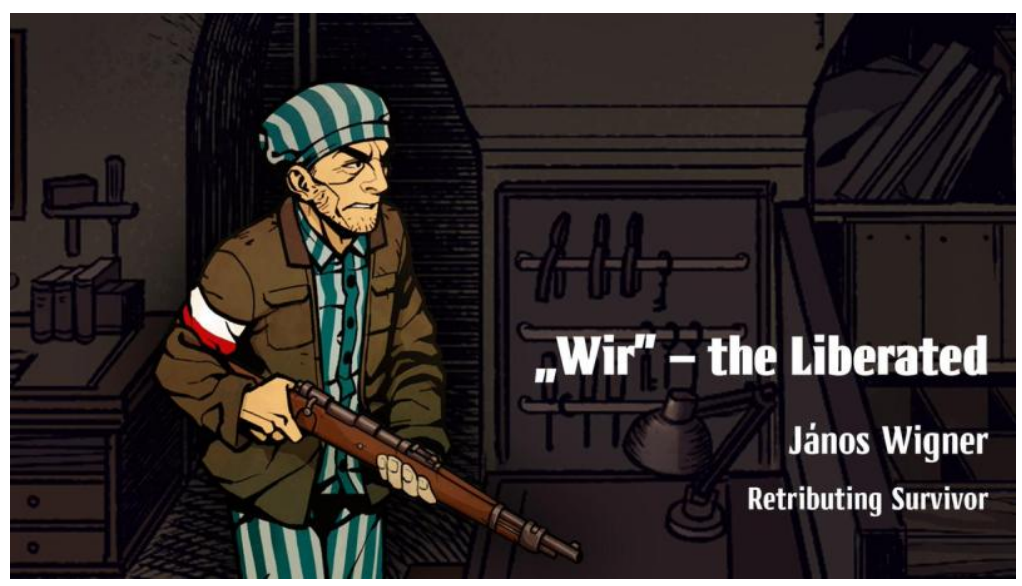

Fuente: Una de las imágenes promocionales del videojuego. 
Warsaw consigue derribar muchos de los retrolugares consolidados en la memoria estética del conflicto dando a la sociedad civil el protagonismo absoluto aunque sea para tomar las armas y enfrentarse a los soldados de ocupación alemanes. También ofrece diferentes novedades como la inclusión de información y contexto acerca del evento, ya que una de las intenciones de sus responsables es dar a conocer el evento histórico fuera de sus fronteras (McCarter, 2019). Un título que, junto al anterior, nos ofrece diferentes formas de representar y recordar un evento histórico de tal magnitud como lo fue la Segunda Guerra Mundial pero que, sin embargo, mantiene la continuidad de la memoria y sirve de puente entre el pasado y el recuerdo oficial de éste en el presente. No cuestiona la identidad nacional sino que la refuerza. No obliga a replantearse el pasado sino que lo confirma. Objetivo compartido con las grandes producciones de contenido histórico.

\section{CONCLUSIÓN}

El videojuego como forma de memoria tiene dos opciones para relacionarse con el pasado: construir o reconstruir. La primera opción le permite formar parte de una cultura de la conmemoración que activa el pasado para el presente bajo la forma de advertencia y crítica, herramientas que capacitan al jugador para afrontar el futuro de la mejor manera posible. La segunda opción subyuga el pasado al presente y lo representa como un puente que asegura la continuidad entre el ayer y el hoy, utilizando al primero como justificación y legitimador del segundo. Esta opción desactiva el ayer como crítica o ejemplo para el presente y lo cosifica convirtiéndolo en un objeto de consumo que puede ser utilizado como objeto propagandístico. Hasta la fecha han sido más los que han escogido la segunda opción quedando relegada la primera a pequeños y escasos ejemplos aún muy desconocidos entre el gran público.

La confrontación con el pasado, la Konstruktion, asume un riesgo y presenta al jugador el sufrimiento de las víctimas del pasado. La necesidad de interacción y la búsqueda de la espectacularidad a través del estilo fotorrealista ha impedido, hasta la fecha, la creación de grandes títulos que apuesten por esta vía. La Rekonstruktion, en cambio, apacigua al jugador y muestra aquello que ya está acostumbrado a ver, no hay riesgo. Es por esto que las grandes inversiones enfocadas a representar digitalmente el pasado han apostado por esta vía, una que asegura la recuperación de la inversión debido a que otros, antes que él, también lo hicieron.

Este debate no es exclusivo del videojuego, también existe y ha existido en el campo del cine. El videojuego, como el cine o la televisión, es capaz de asumir y representar ambas, aquella que obliga a reflexionar y a recordar, y aquella que obliga a la diversión y la seducción. En nosotros está la decisión de premiar a una o a otra y de lograr, como mencionaban los creadores de Through the Darkest of Times, que el videojuego forme parte de la cultura de la conmemoración.

\section{BIBLIOGRAFÍA}

Chang, I. (2016). La violación de Nanking: el holocausto olvidado de la Segunda Guerra Mundial. Madrid: Capitán Swing.

Chapman, A. (2016). Digital Games as History: How Videogames Represent the Past and Offer Access to Historical Practice. Londres, Routledge. 
Chapman, A. y J. Linderoth. (2015). "Exploring the limits of play. A case study of representations of nazism in games", en T. E. Mortensen y J. Linderoth, J., y A. M. Brown (Eds.). The dark side of game play: Controversial issues in playful environments. Londres: Routledge.

Gebhardt, M. (2016). Crimes Unspoken: The Rape of German Women at the End of the Second World War. Cambridge: Polity Press.

Hicks, G. L. (1995). The comfort women: Japan's brutal regime of enforced prostitution in the Second World War. New York: W. W. Norton \& Company.

Jiménez Alcázar, J. F., y Abad Merino, M. (2016). "El pasado como producto de consumo en los medios de ocio" en J. F. Jiménez Alcázar; I. Mugueta Moreno y G. Rodríguez (Coords.) Historia y videojuegos: el impacto de los nuevos medios de ocio sobre el conocimiento histórico. Colección Historia y Videojuegos, Murcia: Ed. Compobell, pp. 9-30.

Jiménez Alcázar, J.F. (2011). "El otro pasado posible: simulación de la Edad Media en los videojuegos" Imago Temporis, 5, pp. 299-340, pp. 496-497.

Jiménez Alcázar, J.F. (2014). "El arte de la guerra medieval: combates digitales y experiencias de juego". Roda da Fortuna, 3(1): 516-546.

Jiménez Alcázar, J.F. (2016). De la edad de los imperios a la guerra total: medievos y videojuegos, Murcia: Editum.

Lipovetsky, G. (2006). El crepúsculo del deber. La ética indolora de los nuevos tiempos democráticos. Barcelona: Anagrama.

Lyons, K. (2018). "Red Dead Redemption 2: game criticised over killing of suffragette". The Guardian. Consultado el 30 de junio de 2020, desde https:/www.theguardian.com/games/2018/nov/07/reddead-redemption-2-game-criticised-over-killing-of-suffragette

McCarter, R. (2019). How Warsaw Captures the Brutality-and Complexity - of the Historical Uprising that Inspired It". EGM. 10 de octubre de 2019. https://egmnow.com/how-warsawcaptures-the-brutality-and-complexity-of-the-historical-uprising-that-inspired-it/. Consulta: $\quad 26$ octubre 2019.

Parker, L. (2017). "The history behind the history of Call of Duty: WW2". Gamespot. Consultado el 23 de julio de 2019, desde https://www.gamespot.com/articles/the-weight-of-history-exploring-thereal-life-insp/1100-6453656/

Rae, G. (2018). "Polonia: cuando el revisionismo histórico se quiere hacer pasar por memoria". Sinpermismo. Consultado 2 septiembre 2019 http://www.sinpermiso.info/textos/polonia-cuando-elrevisionismo-historico-se-quiere-hacer-pasar-por-memoria

Ramsay, D. (2015). «Brutal games: Call of Duty and the cultural narrative of World War II». Cinema Journal, 54(2): 94-113.

Ramsay, D. (2015). American media and the memory of World War Two, Londres: Routledge.

Reyes Mate (2008). La herencia del olvido: ensayos en torno a la razón compasiva. Madrid: Errata Naturae.

Reyes Mate (2018). El tiempo, tribunal de la historia. Madrid: Trotta.

Rosenfeld, G. D. (2014). Hi Hitler! How the Nazi past is being normalized in contemporary culture. Cambridge: Cambridge University Press.

Sánchez-Biosca, V. (2006). Cine de historia, cine de memoria: la representación y sus límites. Madrid: Cátedra.

Sand, S. (2004). El siglo XX en pantalla: cien años a través del cine. Barcelona: Crítica.

Sterczewski, P. (2016). "This Uprising of Mine: Game Conventions, Cultural Memory and Civilian Experience of War in Polish Games". Game Studies, 16, 2. http://gamestudies.org/1602/articles/sterczewski. Consulta: 26 octubre 2019.

Taylor, H. (2019). "How games whitewash Nazism, and the responsibility developers have to history". GamesIndustry. Consultado 1 abril 2020, https://www.gamesindustry.biz/articles/2019-02-28-howgames-whitewash-nazism-and-the-responsibility-developers-have-to-history

Todorov, T. (2013). Los abusos de la memoria. Barcelona: Paidós Ibérica.

Tonini, C. (2019). "El legado del comunismo en Polonia: memorias, nostalgia e indiferencia". Trabajos $\begin{array}{llllll}\text { y } & \text { comunicaciones, } & 49 & \text { (2019). Consultado } & 1 & \text { abril }\end{array}$ https://www.trabajosycomunicaciones.fahce.unlp.edu.ar/article/view/TyCe078/10177. 
Traverso, E (2011). El Pasado, instrucciones de uso: historia, memoria, política. Buenos Aires: Prometeo Libros.

Traverso, E (2013). La historia como campo de batalla: interpretar las violencias del siglo XX. México: Fondo de Cultura Económica. México.

Venegas Ramos, A. (2017). “¿Dónde están los soldados alemanes en los videojuegos de la segunda guerra mundial?" Presura. Consultado 30 marzo 2018 http://www.presura.es/2017/10/26/soldadosalemanes-videojuegos/

Venegas Ramos, A. (2018). "Entre el cine y el videojuego: ética y estética en las producciones sobre la II Guerra Mundial". Videojuegos e Historia: entre el ocio y la cultura. Colección Historia y Videojuegos №5. Editum, Universidad de Murcia.

Venegas Ramos, A. (2018b). "Retrolugares, definición, formación y repetición de lugares, escenarios y escenas imaginados del pasado en la cultura popular y el videojuego". Revista de historiografía (RevHisto), 28: 323-346.

Venegas Ramos, A. (2018b). "El espectáculo ha desterrado a la «realidad» del videojuego. Presura". Consultado 1 abril 2020 https://www.presura.es/blog/2018/01/21/espectaculo-realidad-videojuego/

Venegas Ramos, A. (2019). "Emergencia y formación de subjetividades históricas en los videojuegos de acción contemporáneos. El caso del desembarco de Normandía". Tropelias: Revista de teoría de la literatura y literatura comparada. 31: 116-131.

Venegas Ramos, A. (2019b). El videojuego histórico como memoria literal y memoria ejemplar. Historiografias, 18(2): 30-54.

Venegas Ramos, A. (2019c). "La memoria indolora del videojuego". En Nivel Oculto. Consultado 30 junio 2020 https://niveloculto.com/la-memoria-indolora-del-videojuego/

Venegas Ramos, A. (2020). "Espectáculo, ligereza e instantaneidad en las ficciones digitales del pasado". Presura. Consultado 1 abril $2020 \mathrm{http} / / / \mathrm{www}$. presura.es/blog/2020/01/10/espectaculoligereza-instantaneidad-videojuegos-historicos/

Venegas Ramos, A. (2020b). "El videojuego como memoria estética". Pasado \& Memoria, 20: 277301.

Venegas Ramos, A. (2020c). "Matar nazis y otras maneras virtuales de dirigir la memoria histórica". The Conversation. Consultado 30 junio 2020 https://theconversation.com/matar-nazis-y-otrasmaneras-virtuales-de-dirigir-la-memoria-historica-132358

Venegas Ramos, A. (2020d). "Through the Darkest of Times: recuperar la memoria para afrontar el presente". Presura. Consultado 30 junio $2020 \mathrm{http} / / / \mathrm{www}$. presura.es/blog/2020/02/04/through-thedarkest-of-times-recuperar-la-memoria/

Wilhelm K. M., y Elliott, A. B. R. (eds) (2013). Playing with the past: Digital games and the simulation of history. Nueva York: Bloomsbury.

\title{
Breve currículo:
}

\begin{abstract}
Alberto Venegas Ramos
Licenciado en Historia por la Universidad de Extremadura (2006-2011), Máster en Educación Secundaria Obligatoria por la Universidad de Extremadura (2011-2012), Máster universitario en métodos y técnicas de investigación histórica por la UNED (2012-2013), profesor de Educación Secundaria Obligatoria (desde 2014) y doctorando por la Universidad de Murcia con la tesis doctoral: Historia y Videojuegos: La Segunda Guerra Mundial en la cultura y la sociedad digital contemporánea (2017-2019). Miembro del grupo de investigación del Ministerio de Ciencia, Innovación y Universidades Historia y Videojuegos 2.0: conocimiento, aprendizaje y proyección del pasado en la sociedad digital (HAR2016-78147-P) y autor del libro Pasado interactivo: memoria e historia en el videojuego (Sans Soleil, 2020).
\end{abstract}

